\title{
BRCA2 mutations should be screened early and routinely as markers of poor prognosis: evidence from 8,988 patients with prostate cancer
}

\author{
Ming Cui ${ }^{1}$, Xian-Shu Gao ${ }^{1}$, Xiaobin Gu${ }^{1}$, Wei Guo ${ }^{2}$, Xiaoying $\mathrm{Li}^{1}$, Mingwei $\mathrm{Ma}^{1}$, \\ Shangbin Qin ${ }^{1}$, Xin Qi ${ }^{1}$, Mu Xie ${ }^{1}$, Chuan Peng ${ }^{1}$ and Yun Bai ${ }^{1}$ \\ ${ }^{1}$ Department of Radiation Oncology, Peking University First Hospital, Peking University, Beijing, China \\ ${ }^{2}$ Graduate School of Medicine, Hebei North University, Zhangjiakou, Hebei, China
}

Correspondence to: Xian-Shu Gao, email: doctorgaoxs@126.com

Keywords: BRCA2, mutation, prostate cancer, survival, molecular classification

Received: January 23, $2017 \quad$ Accepted: March 21, $2017 \quad$ Published: March 30, 2017

Copyright: Cui et al. This is an open-access article distributed under the terms of the Creative Commons Attribution License 3.0 (CC BY 3.0), which permits unrestricted use, distribution, and reproduction in any medium, provided the original author and source are credited.

\section{ABSTRACT}

The aim of this study was to focus on clinicopathological characteristics and prognosis in men with prostate cancer ( $\mathrm{PCa}$ ) harboring a breast cancer 2 (BRCA2) gene mutation and to offer convincing evidence to consider BRCA2 mutation as a marker of poor prognosis in the molecular classification of PCa. We searched relevant articles from PubMed, Embase, Web of Science, and the Cochrane Library databases to evaluate the differences in the overall survival (OS) and cancer-specific survival (CSS) between BRCA2 mutation carriers and non-carriers in patients with $\mathrm{PCa}$. We included 525 BRCA2 mutation-carriers and 8,463 non-carriers in total from 10 studies in our meta-analysis. The results showed that carrying a BRCA2 mutation was correlated with a reduced CSS and OS when compared with that of non-carriers, with pooled Hazard Ratios (HRs) of 2.53 (95\% confidence interval (CI): 2.10-3.06, P< 0.001) and 2.21 (95\% CI: 1.64-2.99, $P<0.001)$, respectively. The results also demonstrated that BRCA2 mutation-carriers harbored a higher Gleason Score (GS) ( $>7$ ), TNM stage ( $>$ T3, N1, M1), and risk level than non-carriers. Our meta-analysis showed that a BRCA2 mutation predicted poor survival outcomes in patients with prostate cancer, especially in those undergoing treatments with radiotherapy. Therefore, the use of BRCA2 mutation as a clinical prognostic factor could help stratify the high-risk patients and provide clinical strategies for more effective targeted treatments for patients with prostate cancer.

\section{INTRODUCTION}

Prostate cancer $(\mathrm{PCa})$ was the most prevalent cancer among males in the United States in 2016 [1]. PCa is not only associated with age, prostate-specific antigen (PSA) levels, the Gleason score (GS), and the TNM stage, but also with family history, especially when female relatives have a history of breast and/or ovarian cancer [2].

In recent times, the treatment of $\mathrm{PCa}$ has been facing a bottleneck effect. Evolution into castration-resistant prostate cancer (CRPC) following hormone therapy is observed in an increasing number of patients. At the same time, conventional chemotherapy does not show promising outcomes in CRPC patients with a germline breast cancer 2 (BRCA2) mutation.
Although the $B R C A 2$ mutation is rare and only occurs in approximately $2 \%$ of the population with earlyonset $\mathrm{PCa}$ [3], it increases the risk of $\mathrm{PCa}$ by about six times [4-6]. PCa patients with a BRCA2 mutation have a higher GS scores and have poorer survival outcomes than non-carriers $[7,8]$.

PSA concentration in serum has always been used to screen early-onset PCa and is regarded as a powerful predictor for PCa risk stratification and of biochemical recurrence and prognosis. Recently, increasing numbers of scientists suggest that testing for PSA alone may not be enough and recommend screening for a $B R C A 2$ mutation at the start of PCa treatment.

Currently, patients with prostate cancer undergoing radical treatment survive for longer, with the 10-year 
and 15-year relative survival rates being 98\% and $95 \%$, respectively [1]. For prolonged survival in $\mathrm{PCa}$, molecular classification of BRCA2 mutations has become imperative. Therefore, the objective of this study was to carry out a meta-analysis to focus on clinicopathological characteristics and prognosis in men with PCa harboring a $B R C A 2$ mutation. We have been able to offer some convincing evidence for regarding $B R C A 2$ mutation as a marker of poor prognosis in the molecular classification of PCa through this study.

\section{RESULTS}

\section{Screening and design of the study}

The selection process for our meta-analysis is shown in Figure 1. A search based on keywords on four frequently used databases yielded 776 related articles. The duplicates were eliminated, and 652 articles were screened by reading titles and/or abstracts. After applying the inclusion criteria, only 24 articles remained for fulltext screening. Based on selection criteria, 14 articles were excluded for the following reasons: 5 articles because they were meeting abstracts, 8 articles because they contained insufficient data, and 1 article because it had comparisons between $B R C A 1$ and $B R C A 2$. After screening, 10 articles were included in our meta-analysis. All articles were published between 1998 and 2016.

Details of the 10 included studies are shown in Table 1 [8-17]. We included 525 BRCA2 mutation-carriers and 8,463 non-carriers in total. Nine of the 10 studies were conducted in 6 Western countries including Spain, Australia, Canada, the United States, the United Kingdom, and Iceland. Only 1 study was conducted in an Asian country [9]. The outcomes from 7 studies included only cancer-specific survival (CSS), while the outcome from 1 study included only overall survival (OS). The outcomes from the two remaining studies included both CSS and OS. The Newcastle-Ottawa Scale (NOS) scores for the included studies ranged from 6 to 8 , and the results are presented in Table 1.

\section{Prognostic value of $B R C A 2$ mutation on PCa}

We included ten studies in total in our meta-analysis for elucidating the effects of BRCA2 mutation on CSS and $\mathrm{OS}$ in patients with $\mathrm{PCa}$. The results are shown in Figure 2 and Table 2. The data indicated that BRCA2 mutationcarriers exhibited lower CSS and OS than non-carriers, with a pooled HR of 2.53 (95\% CI: 2.10-3.06) and 2.21 (95\% CI: 1.64-2.99; $P<0.01$ ), respectively.

No statistically significantly difference heterogeneity was found in CSS among the studies $\left(\mathrm{I}^{2}=36 \%, \mathrm{P}_{\mathrm{h}}=0.13\right)$; thus, we performed a subgroup analysis so that we could find the reasons for the heterogeneity. No heterogeneity was found in OS across the studies $\left(\mathrm{I}^{2}=0 \%, \mathrm{P}_{\mathrm{h}}=0.528\right)$.

\section{Subgroup analysis of the effect of $B R C A 2$ mutations on PCa CSS}

To determine the reasons for the heterogeneity seen in CSS and to eliminate the heterogeneity and attain homogeneity among the different subpopulations of patients, we performed a subgroup analysis to investigate the potential sources of heterogeneity across the nine included studies.

The 9 studies that included CSS were divided into 3 subgroups according to 3 different factors: ethnicity, detection methods, and sample size (Table 2). With regard to ethnicity, 8 studies were conducted on Caucasians and 1 study on Asians [9]. BRCA2 mutationcarriers exhibited lower CSS than non-carriers for both Caucasians and Asians, regardless of the ethnicity, with pooled HRs of 2.88 (95\% CI: 2.32-3.58, $P<0.001)$ and 1.66 (95\% CI: $1.12-2.45, P=0.011)$, respectively. The heterogeneity in this case could be eliminated with $\mathrm{I}^{2}=0\left(\mathrm{P}_{\mathrm{h}}=0.13\right)$. There were two main methods to detect $B R C A 2$ mutations at different levels, so we performed a subgroup analysis on detection methods. From among the 9 included studies, 7 studies detected BRCA2 mutations by extracting DNA from peripheral blood, while 2 studies detected $B R C A 2$ mutations at the protein level using immunohistochemistry. The results from all the studies showed that BRCA2 mutation-carriers exhibited lower CSS than non-carriers, regardless of the detection methods used, with pooled HRs of 2.05 (95\% CI: 1.50-2.79, $P<0.001)$ in the protein detection subgroup and 2.87 (95\% CI: $2.26-3.64, P<0.001$ ) in the DNA detection subgroup. For sample sizes, we selected $n=600$ as the cut-off value; there were 5 studies with less than 600 cases and 4 studies with more than 600 cases. BRCA2 mutationcarriers exhibited lower CSS compared with non-carriers even in this subgroup analysis for both the $n<600$ and $n>600$ groups, with pooled HRs of 2.45 (95\% CI: 1.95-3.07, $P<0.001)$ and 2.75 (95\% CI: 1.95-3.87, $P<0.001)$, respectively.

\section{Association of clinicopathological variables between $B R C A 2$ mutation-carriers and non- carriers}

To further explore the correlation of clinicopathological variables between $B R C A 2$ mutationcarriers and non-carriers with $\mathrm{PCa}$, we extracted some impact factors including: GS, TNM stage, and risk stratification of PCa. The results are shown in Table 3 and Figure 3. All the impact factors were associated with a BRCA2 mutation. Pooled odd ratios (ORs) were GS $(>7$ vs. $<=7)(\mathrm{OR}=3.24,95 \%$ CI: $2.36-4.44, P<0.001$; Figure $3 \mathrm{~A}), \mathrm{T}$ stage $(>=\mathrm{T} 3$ vs. $<\mathrm{T} 3)(\mathrm{OR}=1.75,95 \%$ CI: $1.26-2.42, P=0.001$; Figure 3B), N stage (N1 vs. N0) $(\mathrm{OR}=3.90,95 \% \mathrm{CI}: 2.17-7.03, P<0.001$; Figure $3 \mathrm{C})$, $\mathrm{M}$ stage (M1 vs. $\mathrm{M} 0)(\mathrm{OR}=2.47,95 \% \mathrm{CI}: 1.32-4.63$, 
Table 1: Characteristics of included studies

\begin{tabular}{|c|c|c|c|c|c|c|c|c|c|c|c|}
\hline Author & Year & Country & $\begin{array}{c}\text { No.of } \\
\text { BRCA2 } \\
(+)\end{array}$ & $\begin{array}{c}\text { No.of } \\
\text { Non- } \\
\text { carriers }\end{array}$ & Median/Mean age & $\begin{array}{l}\text { Follow-up } \\
\text { (month) }\end{array}$ & outcome & $\begin{array}{c}\text { Levels } \\
\text { of detect } \\
\text { BRCA2 }\end{array}$ & $\begin{array}{c}\text { Proportion of } \\
\text { patients with } \\
\text { metastasis }\end{array}$ & $\begin{array}{c}\text { Median/Mean PSA } \\
\text { level (ng/ml) }\end{array}$ & $\begin{array}{l}\text { NOS } \\
\text { Score }\end{array}$ \\
\hline Kim [9] & 2016 & Korea & 212 & 291 & $66.0(44.0-89.0)$ & $44.0(12-142)$ & CSS & Protein & $3.1 \%$ & $8.0(1.0-93.0)$ & 7 \\
\hline Castro [10] & 2015 & Spain & 67 & 1,235 & $\begin{array}{l}\text { (+) } 58.7(41.7-77.5) \\
(-) 57.1(36.0-85.8)\end{array}$ & NA & CSS & DNA & Not reported & $\begin{array}{l}(+) \quad 8.5 \quad(0.5-68.5) \\
(-) 10.1(0.5-143)\end{array}$ & 8 \\
\hline Bolton [11] & 2015 & Australia & 31 & 59 & $\begin{array}{l}\text { (+) } 65.0(43.0-84.0) \\
(-) 66.0(45.0-87.0)\end{array}$ & 88.8 & CSS & Protein & $\begin{array}{l}\text { BRCA2 (+): } 11.1 \% \\
\text { BRCA2 (-): } 3.3 \%\end{array}$ & $\begin{array}{l}\text { (+) } 20.95(0.4-3750) \\
(-) 10.0(2.0-195)\end{array}$ & 6 \\
\hline Akbari [12] & 2014 & Canada & 26 & 1,878 & $\begin{array}{l}(+) 67.0(49-90)(-) \\
65.0\end{array}$ & $104.4(1.2-144)$ & CSS & DNA & BRCA2 (+): $25 \%$ & $\begin{array}{l}(+) 56.3 \\
(-) 13.3\end{array}$ & 7 \\
\hline Castro [8] & 2013 & Spain & 61 & 1,940 & $\begin{array}{l}\text { (+) } 57.6(41.7-88) \\
(-) 57.2(32.3-88.9)\end{array}$ & $50.0(3.5-245)$ & OS CSS & DNA & $\begin{array}{l}\text { Approximately : } \\
\text { BRCA2 (+): } 31.1 \% \\
\text { BRCA2 (-): } 12.8 \%\end{array}$ & $\begin{array}{l}(+) 15.1(0.5-761) \\
(-) 11.3(0.2-7800)\end{array}$ & 8 \\
\hline Thorne [13] & 2011 & Australia & 40 & 97 & $\begin{array}{l}(+) 64.9(43.0-84.0) \\
(-) 66.8(33.0-87.0)\end{array}$ & NA & OS CSS & DNA & $\begin{array}{l}\text { BRCA2 }(+): 17.5 \% \\
\text { BRCA2 }(-): 4.1 \%\end{array}$ & NA & 6 \\
\hline Edwards [14] & 2010 & UK & 21 & 1,587 & NA & NA & OS & DNA & $29.4 \%$ & NA & 6 \\
\hline $\begin{array}{l}\text { Gallagher } \\
{[15]}\end{array}$ & 2010 & USA & 20 & 806 & $\begin{array}{l}\text { (+) } 62.0(40.8-83.0) \\
(-) 68.2(42.7-94.4)\end{array}$ & 96 & CSS & DNA & Not reported & $\begin{array}{l}(+) 7.0(6.0-9.0)(-) \\
7.0(2.0-10.0)\end{array}$ & 7 \\
\hline $\begin{array}{l}\text { Tryggvadóttir } \\
{[16]}\end{array}$ & 2007 & Iceland & 30 & 497 & $\begin{array}{l}\text { (+) } 69.0(48.0-84.0) \\
(-) 74.0(50.0-93.0)\end{array}$ & NA & CSS & DNA & $\begin{array}{l}\text { Approximately : } \\
\text { BRCA2 (+): } 55.2 \% \\
\text { BRCA2 (-): } 24.6 \%\end{array}$ & NA & 7 \\
\hline Edwards [17] & 1998 & UK & 17 & 73 & NA & NA & CSS & DNA & Not reported & NA & 6 \\
\hline
\end{tabular}

Abbreviations: NA: not available; CSS: cancer-specific survival; OS: overall survival; PSA: prostate-specific antigen.

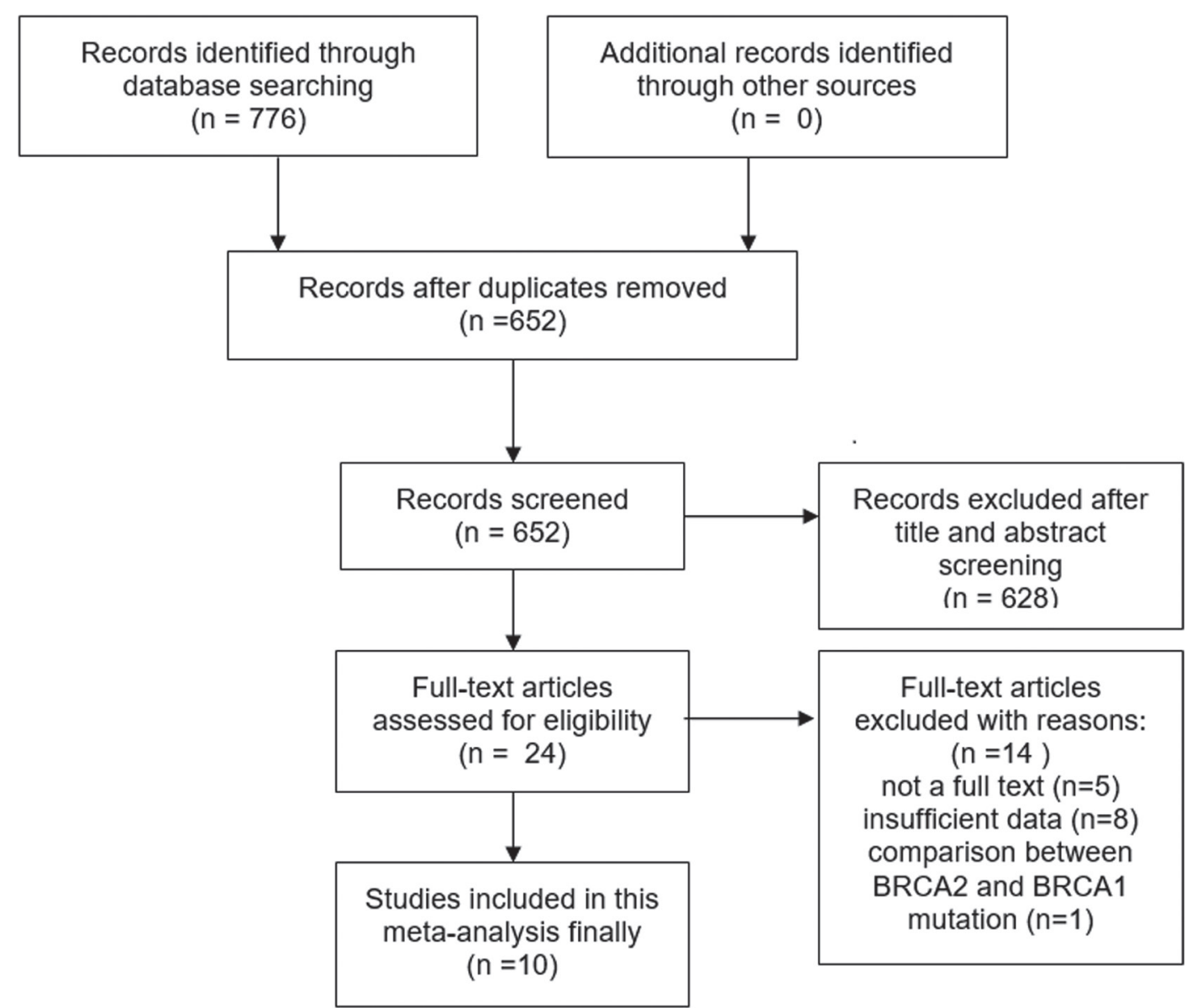

Figure 1: The flow diagram of articles selection. 
Table 2: Main results of the meta-analysis

\begin{tabular}{|c|c|c|c|c|c|c|c|c|c|}
\hline & \multirow[t]{2}{*}{ Factors } & \multirow{2}{*}{$\begin{array}{c}\text { No.of } \\
\text { studies }\end{array}$} & \multirow{2}{*}{$\begin{array}{c}\text { No.of } \\
\text { BRCA2 }(+)\end{array}$} & \multirow{2}{*}{$\begin{array}{l}\text { No.of Non- } \\
\text { carriers }\end{array}$} & \multirow{2}{*}{$\begin{array}{l}\text { Effects } \\
\text { model }\end{array}$} & \multirow[t]{2}{*}{ HR (95\% cI) } & \multirow[t]{2}{*}{$P$} & \multicolumn{2}{|c|}{ Heterogeneity } \\
\hline & & & & & & & & $I^{2}(\%)$ & $\boldsymbol{P}_{\mathrm{h}}$ \\
\hline \multirow[t]{10}{*}{ CSS } & Overall & 9 & 504 & 6,876 & Fixed & $2.53(2.10-3.06)$ & $<0.001$ & 36 & 0.13 \\
\hline & \multicolumn{9}{|l|}{ Ethnicity } \\
\hline & Caucasian & 8 & 292 & 6,585 & Fixed & $2.88(2.32-3.58)$ & $<0.001$ & 0 & 0.469 \\
\hline & Asian & 1 & 212 & 291 & Fixed & $1.66(1.12-2.45)$ & 0.011 & NA & \\
\hline & \multicolumn{9}{|c|}{ Detect methods } \\
\hline & Protein & 2 & 243 & 350 & Fixed & $2.05(1.50-2.79)$ & $<0.001$ & 67.1 & 0.081 \\
\hline & DNA & 7 & 261 & 6526 & Random & $2.87(2.26-3.64)$ & $<0.001$ & 9.4 & 0.357 \\
\hline & \multicolumn{9}{|l|}{ Sample size } \\
\hline & $<600$ & 5 & 330 & 1,017 & Random & $2.45(1.95-3.07)$ & $<0.001$ & 52.8 & 0.076 \\
\hline & $>600$ & 4 & 174 & 5,859 & Fixed & $2.75(1.95-3.87)$ & $<0.001$ & 19.6 & 0.292 \\
\hline OS & Overall & 3 & 122 & 3,624 & Fixed & $2.21(1.64-2.99)$ & $<0.001$ & 0 & 0.528 \\
\hline
\end{tabular}

Abbreviations: $\mathrm{P}_{\mathrm{h}}: P$ value of $Q$ test for heterogeneity.

$P=0.005$; Figure 3D), and risk stratification of $\mathrm{PCa}$ (high vs. low or intermediate; Figure $3 \mathrm{E})(\mathrm{OR}=1.43,95 \% \mathrm{CI}$ : $0.95-2.14, P=0.087)$, respectively.

\section{Sensitivity analysis}

To test the results of this meta-analysis, each study was individually eliminated by turn and the pooled data was recalculated. The results of the sensitivity analysis for CSS and OS are shown in Figure 4. Since the corresponding pooled HR did not substantially change, we could confirm our results [18].

\section{Publication bias}

Publication bias was assessed using the Begg's and Egger's tests. The results of the Begg's test demonstrated that there was no significant publication bias in CSS $(P=0.175)$ and OS $(P=0.296)$ (Figure 5). The same results could be concluded by using Egger's test for CSS $(P=0.07)$ and OS $(P=0.057)$. Furthermore, the same conclusions were obtained when tested for the correlation of clinicopathological variables with $B R C A 2$ mutations in PCa (Table 3).

\section{DISCUSSION}

To the best of our knowledge, this is the first meta-analysis that concentrated on $\mathrm{PCa}$ screening and prognosis with in patients with $B R C A 2$ mutations. In this meta-analysis, we demonstrated that a $B R C A 2$ mutation predicted a lower survival in patients with $\mathrm{PCa}$, both for Caucasians and Asian. Our results were consistent with those of other studies, which show that a $B R C A 2$ mutation not only enhances the risk of PCa, but also doubles the PSA levels [8, 19, 20]. For this reason, only PSA screening may not be enough for patients with $\mathrm{PCa}$ at early stages, so we suggest that the $B R C A 2$ gene be screened routinely for mutations as a biomarker of poor prognosis in the molecular classification of $\mathrm{PCa}$, thus offering scope in the planning for more effective clinical strategies for treatment.

A BRCA2 mutation was first detected in breast or ovarian cancer in females and was significantly associated with family history, especially when relatives had breast, ovarian, or prostate cancer. First, family history increases the risk of morbidity associated with PCa by about twice than that seen for patients in the general population and increases the risk of early onset (diagnosed before 60 years of age) by about four times when compared with the general population. This is a direct influence of family history on PCa onset and prognosis. Second, it is thought that families with a clearly dominant predisposition to breast or ovarian cancer harbor germline mutations in $B R C A 2$ genes. BRCA2 mutations predicted poor survival outcomes as seen in our meta-analysis. BRCA2 mutations are known to elevate the risk of not only breast and ovarian cancer, but also other cancers like PCa. This is an indirect influence of family history on PCa onset and prognosis [2-5].

$B R C A 2$ mutations were also associated with GS, TNM stage, and risk stratification, as demonstrated by our meta-analysis (Table 3 ). With regard to the GS, our results indicated that GS $>7$ was more frequent in $B R C A 2$ mutation-carriers than non-carriers. Mitra et al. also observed that the GS was higher in $B R C A 2$ mutation-carriers [7]. A higher GS correlates with poor survival and a higher 
Table 3: Meta-analysis of the association on clinicopathologic features between BRCA2+ and noncarriers with prostate cancer

\begin{tabular}{|l|c|c|c|c|c|c|c|c|c|c|}
\hline \multicolumn{1}{c}{ Variable } & $\begin{array}{c}\text { No.of } \\
\text { studies }\end{array}$ & $\begin{array}{c}\text { No.of } \\
\text { BRCA2(+) }\end{array}$ & $\begin{array}{c}\text { No.of Non- } \\
\text { carriers }\end{array}$ & $\begin{array}{c}\text { Effects } \\
\text { model }\end{array}$ & OR (95\% CI) & \multicolumn{3}{c}{$\begin{array}{c}\text { Heterogeneity } \\
\text { Publication } \\
\text { begg's p }\end{array}$} \\
\hline GS (> 7 vs. $<=7)$ & 6 & 231 & 3,722 & Fixed & $3.24(2.36-4.44)$ & $<0.001$ & 21.8 & 0.27 & 0.26 \\
\hline T stage (> = T3 vs. $<$ T3) & 4 & 176 & 2,859 & Fixed & $1.75(1.26-2.42)$ & 0.001 & 0 & 0.459 & 0.089 \\
\hline N stage (N1 vs. N0) & 3 & 139 & 2,367 & Fixed & $3.90(2.17-7.03)$ & $<0.001$ & 0 & 0.589 & 0.296 \\
\hline M stage (M1 vs. M0) & 2 & 90 & 1,999 & Fixed & $2.47(1.32-4.63)$ & 0.005 & 0 & 0.737 & 1 \\
\hline Risk (High vs. $<$ High) & 2 & 101 & 2,510 & Fixed & $1.43(0.95-2.14)$ & 0.087 & 0 & 0.338 & 1 \\
\hline
\end{tabular}

Abbreviations: $\mathrm{P}_{\mathrm{h}}: P$ value of $Q$ test for heterogeneity.

\begin{tabular}{|c|c|c|c|}
\hline Study & & & $\%$ \\
\hline ID A: CSS & & ES $(95 \% \mathrm{Cl})$ & Weight \\
\hline $\operatorname{Kim}(2016)$ & $\rightarrow$ & $1.66(1.12,2.45)$ & 23.30 \\
\hline Castro(2015) & & $2.78(1.53,5.04)$ & 10.04 \\
\hline Bolton(2015) & & $2.94(1.76,4.90)$ & 13.61 \\
\hline Akbari(2014) & & $3.48(1.58,7.72)$ & 5.67 \\
\hline Castro(2013) & $\rightarrow$ & $1.92(1.09,3.39)$ & 11.09 \\
\hline Thorne(2013) & & $3.79(1.95,7.35)$ & 8.11 \\
\hline Gallagher(2010) & & $5.48(2.03,14.79)$ & 3.62 \\
\hline Tryggvadóttir(2007) & & $3.42(2.12,5.51)$ & 15.65 \\
\hline Edwards(1998) & $\rightarrow$ & $1.90(1.01,3.58)$ & 8.91 \\
\hline Overall $(\mathrm{I}-\mathrm{squared}=36.0 \%, \mathrm{p}=0.130)$ & & $2.53(2.10,3.06)$ & 100.00 \\
\hline .0676 & 1 & 14.8 & \\
\hline Study & & & $\%$ \\
\hline ID B: OS & & $\mathrm{ES}(95 \% \mathrm{Cl})$ & Weight \\
\hline Castro(2013) & & $1.87(1.14,3.07)$ & 36.89 \\
\hline Thorne(2011) & & $\rightarrow 2.87(1.63,5.03)$ & 28.51 \\
\hline Edwards(2010) & & $2.14(1.28,3.56)$ & 34.60 \\
\hline Overall $(I-$ squared $=0.0 \%, p=0.528)$ & & $2.21(1.64,2.99)$ & 100.00 \\
\hline .199 & I & 5.03 & \\
\hline
\end{tabular}

Figure 2: The forest plot of (A) CSS and (B) OS with BRCA2 mutation. 
requirement for needle biopsy, particularly in patients with GS 8-10 [21]. With regard to the TNM stage, our results showed that BRCA2 mutations were correlated with T3-T4, $\mathrm{N} 1$, and M1 stages. A high TNM stage also correlates with high mortality in $\mathrm{PCa}$ and is a predictor of poor prognosis, which was also found in other studies [8, 9]. PCa prognosis also depends on risk stratification; each risk level has corresponding treatments in the National Comprehensive
Cancer Network (NCCN) guidelines. This meta-analysis showed that risk stratification was also relevant to $B R C A 2$ mutations. BRCA2 mutation-carriers had a higher risk than non-carriers, though there was no statistically significantly difference $(P=0.087)$ due to the limited number of studies (only two studies) included in this group.

We analyzed the proportion of PCa patients with metastasis (N1 or M1) in all included studies and found
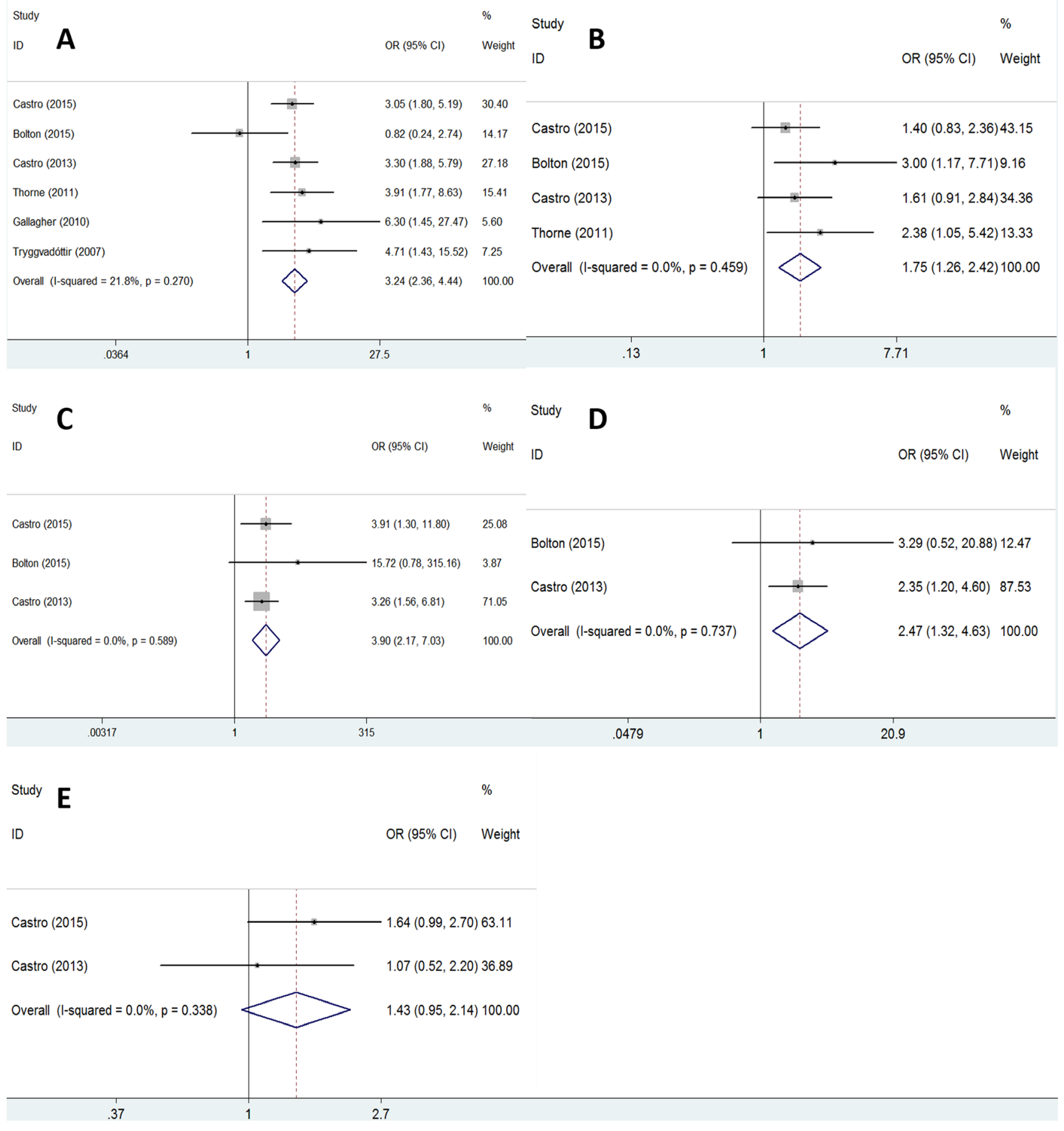

Figure 3: The forest plot of association between clinicopathologic variables and BRCA2 mutation: GS (A); T stage (B); N stage (C); M stage (D); risk-stratification (E). 
that $B R C A 2$ mutation-carriers have a significantly higher rate of metastasis than non-carriers. This implies that $B R C A 2$ mutation-carriers had a poorer prognosis with a lower metastasis-free survival (MFS) after treatment than that seen in non-carriers.

$B R C A 2$ mutations were also correlated with radiotherapy outcomes. In Castro et al. [13], a BRCA2 mutation predicted poor CSS in all patients. However, in the subgroup analysis, no significant differences after radical prostatectomy (RP) were observed between $B R C A 2$ mutation-carriers and non-carriers $(P=0.566)$. However, CSS after radiation therapy (RT) was significantly higher in non-carriers than in mutation-carriers $(P<0.001)$. This indicated that a $B R C A 2$ mutation may predict poor CSS after RT rather than RP, but this conclusion needs many clinical trials for verification.

After exposure to ionizing radiation in human cells, DNA lesions can be observed due to DNA single-strand breaks (SSBs) and double-strand breaks (DSBs [22].
When DNA strands break, repair mechanisms are initiated. SSBs are mostly repaired by base excision repair (BER), nucleotide excision repair (NER), or mismatch repair pathways using an intact complementary DNA strand as a template. DSBs are the foremost form among all the lesions and its repair plays an important role in maintaining genomic integrity and stability. The repair pathways of DSBs in human cells are non-homologous end-joining (NHEJ) and homologous recombination (HR) [23-26]. BRCA2 is considered to enhance genomic stability through error-free repair of DSBs by HR [27, 28]. A BRCA2 mutation makes this unavailable and the repair pathways transition from HR to NHEJ, leading to genomic instability [28, 29].

Poly (ADP-ribose) polymerase-1 (PARP1) had a long exploring history since 1963 [30]. PARP1 is associated with the repair of SSBs through BER [31, 32]. When PARP1 function is inhibited, DNA lesions may be repaired by HR instead of BER. Under this circumstance,
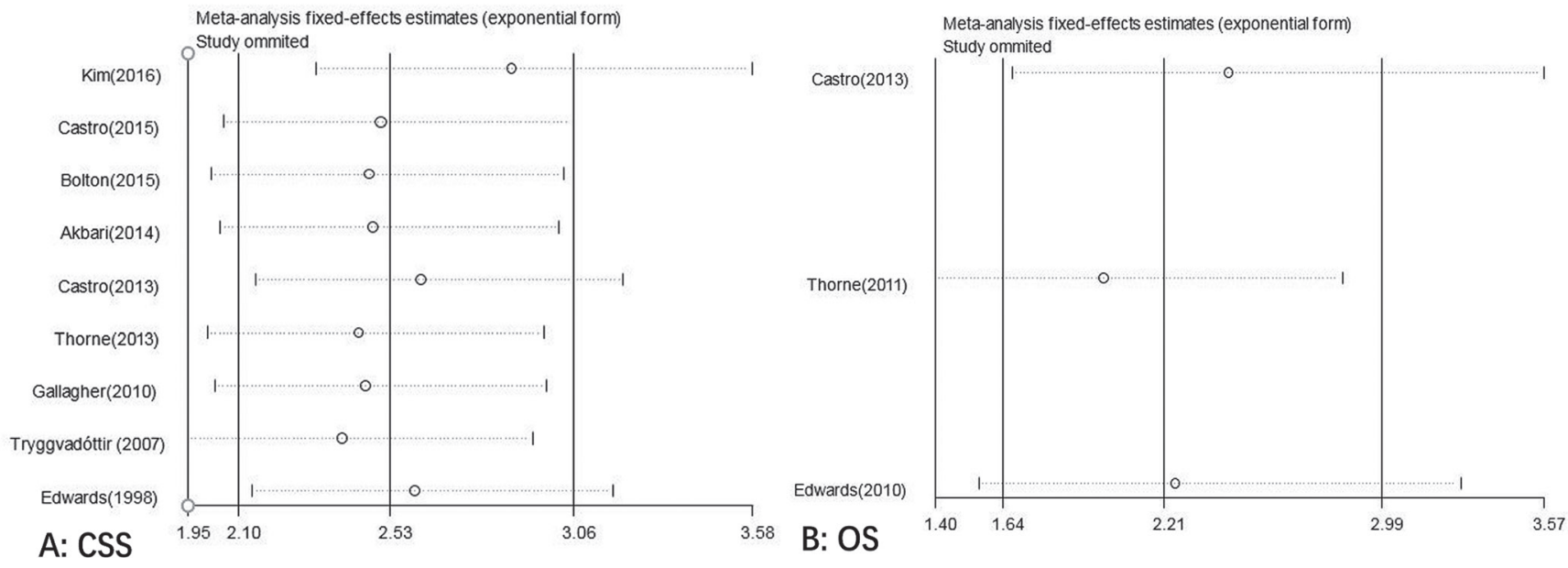

Figure 4: Sensitivities analysis of (A) CSS and (B) OS with BRCA2 mutation.
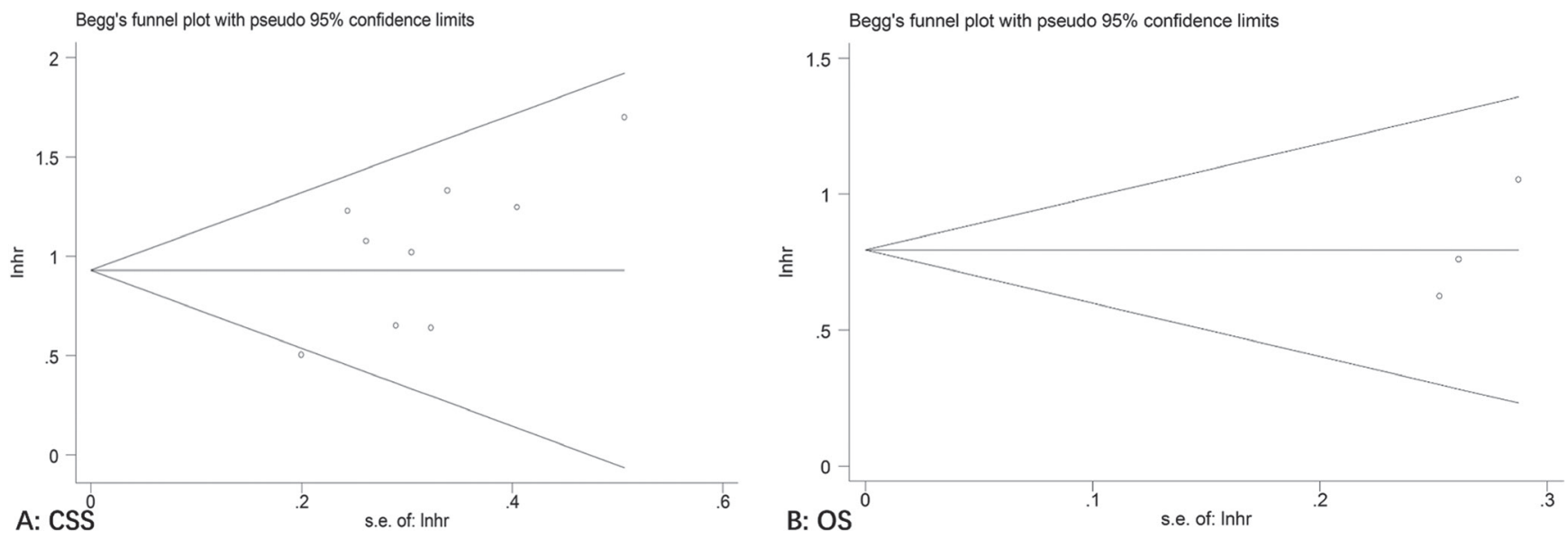

Figure 5: Begg's funnel plot of publication bias test for (A) CSS and (B) OS with BRCA2 mutation. 
if $B R C A 2$ is also mutated, the dual effects make repair abnormal and lead to cancer cell death [28]. According to this theory, PARP1 inhibition could be used in $B R C A 2$ mutation-carriers to obtain satisfactory therapeutic outcomes. Some studies demonstrated that PARP1 inhibition was highly selective in human tumors with BRCA2 mutations [33]. Olaparib, an inhibitor of PARP1, obtained accelerated approval from the Food and Drug Administration (FDA) in December 2014. It had shown promising therapeutic effects in $B R C A 2$ mutation-carrier patients with triple-negative breast cancer and sporadic serous ovarian cancer in females and CRPC and metastatic PCa in males [32-34].

Patients with metastatic PCa and CRPC are thought to be associated with DNA repair defects like those seen with $B R C A 2$ mutations. These patients can benefit from Olaparib than $B R C A 2$ mutation non-carriers with prolonged OS (median, 9.8 vs. 2.7 months; $P<0.001$ ) and PFS (median, 13.8 vs. 7.5 months; $P=0.05$ ) [34].

There are two major strengths of this meta-analysis. First, we have an enormous sample size with 8,988 patients (525 BRCA2 mutation-carriers and 8,463 noncarriers), which make the results convincing. Second, both Caucasian and Asian patients are included in this metaanalysis; therefore, our results are applicable in these two ethnic populations.

There are three limitations in this meta-analysis. First, our results are concluded from 10 articles that are all retrospective studies, which provide less sufficient clinical evidence than randomized control trial (RCT) studies. Second, only one study involve Asian men and may be inadequately representative. Finally, the higher incidence of PCa in African-Americans demonstrates that genetic factors are an important determinant of the variations in risk at the population level [2]. However, our included studies do not contain this population, and therefore, a subset analysis could not be performed for this ethnicity.

In conclusion, our meta-analysis showed that patients with $\mathrm{PCa}$ harboring a $B R C A 2$ mutation had poor survival both in Caucasian and Asian populations. Therefore, a BRCA2 mutation as a clinical prognostic factor could help stratify the high-risk patients and provide inputs in the planning of specific and more effective treatments. Thus, we suggest that BRCA2 mutation as a biomarker of poor prognosis could contribute in the molecular classification of PCa.

\section{MATERIALS AND METHODS}

This meta-analysis was performed following the Preferred Reporting Items for Systematic Reviews and MetaAnalyses (PRISMA) Statement guidelines strictly [35].

\section{Literature search}

We searched relevant articles that were published prior to July 31, 2016 from PubMed, Embase, Web of Science, and the Cochrane Library databases. The key terms included "Breast Cancer 2" or "BRCA2," "genes," "mutation," "survival," "prognosis" or "prognostic," "predict" or "predictive," "treatment," "biomarker," and "prostate cancer" or "prostate neoplasms" or "prostate carcinoma" or "PCa." The searching strategies were keywords combined with a manual search from references in all eligible studies.

\section{Inclusion and exclusion criteria}

Articles were selected on the basis of the following inclusion criteria: (1) comparison between PCa patients with a $B R C A 2$ mutation and non-carriers; (2) a $B R C A 2$ mutation was confirmed in postoperative pathological specimens or detected in the plasma; (3) survival-associated outcomes including OS, CSS, MFS, progression-free survival (PFS), disease-specific survival (DSS) and biochemical recurrence-free survival (bRFS); (4) sufficient data extraction from the studies to enable calculation of HRs and 95\% CIs; and (5) the sample sizes larger than 30 .

Furthermore, the studies were excluded if: (1) studies were not performed on human subjects but on cells or animals; (2) articles were not written in English; (3) the data were insufficient for calculation; or (4) articles were not full-text or were review articles.

\section{Data extraction and quality assessment}

Two researchers (M.C and XB.G) extracted the data from the eligible studies independently, and any disagreements were resolved by reconsidering and discussing with our senior investigator (XS.G). The following data were extracted from the eligible studies according to a predefined spreadsheet: first author's name, year of publication, author's country, number of patients with a $B R C A 2$ mutation, number of non-carriers, age, follow-up duration, survival outcomes, levels of detected BRCA2, proportion of patients with metastasis, PSA levels, and NOS scores.

Quality assessment was performed on each study by three investigators independently (M.C, W.G, and XB.G) using the NOS quality assessment criteria [36]. The NOS scoring system uses stars to evaluate the methodological quality on three aspects: selection, comparability, and outcome. Each aspect has two to four stars out of a total of nine stars for the NOS scoring system. We regarded studies with more than six stars as high-quality studies. 


\section{Statistical analysis}

The STATA 12.0 software (Stata Corp LP, College Station, TX, USA) was used to perform our meta-analysis. HRs, ORs, and their 95\% CIs were calculated from the included studies. HR $>1$ meant lower survival rates for BRCA2-mutation carriers compared with non-carriers [37]. We extracted HRs and 95\% CIs from every eligible study and for those studies from which the data could not be extracted directly, we estimated the date from survival curves [38].

\section{Assessment of heterogeneity}

The heterogeneity of pooled results was tested with the Cochran's $Q$ test and Higgins I-squared statistic. We defined significant heterogeneity if $\mathrm{I}^{2}>50 \%$ and $\mathrm{P}_{\mathrm{h}}$ value $<0.1$ at the same time. Under this circumstance, the random effects model would be chosen. Otherwise, the fixed effects model was selected.

\section{Assessment of reporting bias}

Publication bias was evaluated by the Begg's and Egger's funnel plot tests, and $P<0.05$ was thought to be statistically significant. For evaluating the stability of the results, we performed a sensitivity analysis.

\section{Subgroup analysis}

For subgroup analysis, all studies were divided into subgroups based on ethnicity detection methods and sample size. Association analysis was also performed for variables including GS, TNM stage, and risk stratification of $\mathrm{PCa}$.

\section{Abbreviations}

Prostate cancer $=\mathrm{PCa}$; Breast Cancer $2=\mathrm{BRCA} 2$; Overall survival $=\mathrm{OS}$; Cancer-specific survival $=\mathrm{CSS}$; Hazard Ratios = HRs; Confidence interval = CI; Odds ratio $\mathrm{s}=$ ORs; Prostate-specific antigen $=$ PSA; Gleason score $=$ GS; Castration-Resistant Prostate Cancer $=$ CRPC; Newcastle-Ottawa Scale $=$ NOS; Single-strand breaks $=$ SSB; Double-strand breaks = DSB; Base excision repai $\mathrm{r}=\mathrm{BER}$; Nucleotide excision repair $=\mathrm{NER}$; Non-homologous end-joining $=$ NHEJ; Homologous recombination $=$ HR; Poly (ADP-ribose) polymerase- 1 $=$ PARP- 1 ; Food and Drug Administration = FDA; Randomized control trial $=\mathrm{RCT}$; Preferred Reporting Items for Systematic Reviews and Meta-Analyses = PRISMA; Progression-free survival = PFS; Diseasespecific survival $=$ DSS; Metastasis-free survival $=$ MFS; biochemical recurrence free survival $=$ bRFS; National Comprehensive Cancer Network $=$ NCCN.

\section{Authors' contributions}

M,C, XB, G, XS, G designed the study, collected, analyzed, and interpreted the data, and wrote the article. W,G, XY,L, MW,M, SB,Q, X,Q, M,X, C,P, $\mathrm{Y}, \mathrm{B}$ participated in the study, collected, analyzed, and interpreted data, and critically revised the article. All authors read and approved the final manuscript.

\section{ACKNOWLEDGMENTS}

This work was supported by a grant from the Clinical Features Research of Capital (No. Z141107002514160).

\section{CONFLICTS OF INTEREST}

The authors declare no conflicts of interest.

\section{REFERENCES}

1. Miller KD, Siegel RL, Lin CC, Mariotto AB, Kramer JL, Rowland JH, Stein KD, Alteri R, Jemal A. Cancer treatment and survivorship statistics, 2016. CA Cancer J Clin. 2016; 66:271-289.

2. Attard G, Parker C, Eeles RA, Schroder F, Tomlins SA, Tannock I, Drake CG, de Bono JS. Prostate cancer. Lancet. 2016; 387:70-82.

3. Edwards SM, Kote-Jarai Z, Meitz J, Hamoudi R, Hope Q, Osin P, Jackson R, Southgate C, Singh R, Falconer A, Dearnaley DP, Ardern-Jones A, Murkin A, et al. Two percent of men with early-onset prostate cancer harbor germline mutations in the BRCA2 gene. Am J Hum Genet. 2003; 72:1-12.

4. Breast Cancer Linkage Consortium. Cancer risks in BRCA2 mutation carriers. J Natl Cancer Inst. 1999; 91:1310-1316.

5. Thompson D, Easton D. Variation in cancer risks, by mutation position, in BRCA2 mutation carriers. Am J Hum Genet. 2001; 68:410-419.

6. Levy-Lahad E, Friedman E. Cancer risks among BRCA1 and BRCA2 mutation carriers. Br J Cancer. 2007; 96:11-15.

7. Mitra A, Fisher C, Foster CS, Jameson C, Barbachanno Y, Bartlett J, Bancroft E, Doherty R, Kote-Jarai Z, Peock S, Easton D, Eeles R, Collaborators IAE. Prostate cancer in male BRCA1 and BRCA2 mutation carriers has a more aggressive phenotype. Br J Cancer. 2008; 98:502-507.

8. Castro E, Goh C, Olmos D, Saunders E, Leongamornlert D, Tymrakiewicz M, Mahmud N, Dadaev T, Govindasami K, Guy M, Sawyer E, Wilkinson R, Ardern-Jones A, et al. Germline BRCA mutations are associated with higher risk of nodal involvement, distant metastasis, and poor survival outcomes in prostate cancer. J Clin Oncol. 2013; 31:1748-1757.

9. Kim SH, Park WS, Yun SI, Joo J, Joung JY, Seo HK, Chung J, Lee GK, Lee KH. Overexpression of BRCA1 
or BRCA2 in prostatectomy specimens is predictive of biochemical recurrence after radical prostatectomy. Histopathology. 2016; 68:673-679.

10. Castro E, Goh C, Leongamornlert D, Saunders E, Tymrakiewicz M, Dadaev T, Govindasami K, Guy M, Ellis S, Frost D, Bancroft E, Cole T, Tischkowitz M, et al. Effect of BRCA Mutations on Metastatic Relapse and Cause-specific Survival After Radical Treatment for Localised Prostate Cancer. Eur Urol. 2015; 68:186-193.

11. Bolton D, Cheng Y, Willems-Jones AJ, Li J, Niedermeyr E, Mitchell G, Clouston D, Lawrentschuk N, Sliwinski A, Fox S, Thorne H. Altered significance of D'Amico risk classification in patients with prostate cancer linked to a familial breast cancer (kConFab) cohort. Bju Int. 2015; 116:207-212.

12. Akbari MR, Wallis CJ, Toi A, Trachtenberg J, Sun P, Narod SA, Nam RK. The impact of a BRCA2 mutation on mortality from screen-detected prostate cancer. Br J Cancer. 2014; 111:1238-1240.

13. Thorne H, Willems AJ, Niedermayr E, Hoh IM, Li J, Clouston D, Mitchell G, Fox S, Hopper JL, Bolton D. Decreased prostate cancer-specific survival of men with BRCA2 mutations from multiple breast cancer families. Cancer Prev Res (Phila). 2011; 4:1002-1010.

14. Edwards SM, Evans DG, Hope Q, Norman AR, Barbachano Y, Bullock S, Kote-Jarai Z, Meitz J, Falconer A, Osin P, Fisher C, Guy M, Jhavar SG, et al. Prostate cancer in BRCA2 germline mutation carriers is associated with poorer prognosis. Br J Cancer. 2010; 103:918-924.

15. Gallagher DJ, Gaudet MM, Pal P, Kirchhoff T, Balistreri L, Vora K, Bhatia J, Stadler Z, Fine SW, Reuter V, Zelefsky M, Morris MJ, Scher HI, et al. Germline BRCA mutations denote a clinicopathologic subset of prostate cancer. Clin Cancer Res. 2010; 16:2115-2121.

16. Tryggvadottir L, Vidarsdottir L, Thorgeirsson T, Jonasson JG, Olafsdottir EJ, Olafsdottir GH, Rafnar T, Thorlacius S, Jonsson E, Eyfjord JE, Tulinius H. Prostate cancer progression and survival in BRCA2 mutation carriers. J Natl Cancer Inst. 2007; 99:929-935.

17. Edwards SM, Dunsmuir WD, Gillett CE, Lakhani SR, Corbishley C, Young M, Kirby RS, Dearnaley DP, Dowe A, Ardern-Jones A, Kelly J, Spurr N, Barnes DM, Eeles RA. Immunohistochemical expression of BRCA2 protein and allelic loss at the BRCA2 locus in prostate cancer. CRC/ BPG UK Familial Prostate Cancer Study Collaborators. Int J Cancer. 1998; 78:1-7.

18. Gu X, Gao XS, Cui M, Xie M, Peng C, Bai Y, Guo W, Han L, Gu X, Xiong W. Clinicopathological and prognostic significance of platelet to lymphocyte ratio in patients with gastric cancer. Oncotarget. 2016; 7:49878-49887. doi: 10.18632/oncotarget.10490.

19. Bryant HE. The Clinical Impact of BRCA2 Loss in Prostate Cancer. Eur Urol. 2016; 69:996-997.

20. Bancroft EK, Page EC, Castro E, Lilja H, Vickers A, Sjoberg D, Assel M, Foster CS, Mitchell G, Drew K,
Maehle L, Axcrona K, Evans DG, et al. Targeted prostate cancer screening in BRCA1 and BRCA2 mutation carriers: results from the initial screening round of the IMPACT study. Eur Urol. 2014; 66:489-499.

21. Ozdamar SO, Sarikaya S, Yildiz L, Atilla MK, Kandemir B, Yildiz S. Intraobserver and interobserver reproducibility of WHO and Gleason histologic grading systems in prostatic adenocarcinomas. Int Urol Nephrol. 1996; 28:73-77.

22. Shelke S, Das B. Dose response and adaptive response of non-homologous end joining repair genes and proteins in resting human peripheral blood mononuclear cells exposed to gamma radiation. MUTAGENESIS. 2015; 30:365-379.

23. Wood RD, Mitchell M, Lindahl T. Human DNA repair genes, 2005. Mutat Res. 2005; 577:275-283.

24. Yin HL, Suzuki Y, Matsumoto Y, Tomita M, Furusawa Y, Enomoto A, Morita A, Aoki M, Yatagai F, Suzuki T, Hosoi Y, Ohtomo K, Suzuki N. Radiosensitization by hyperthermia in the chicken B-lymphocyte cell line DT40 and its derivatives lacking nonhomologous end joining and/ or homologous recombination pathways of DNA doublestrand break repair. Radiat Res. 2004; 162:433-441.

25. Loser DA, Shibata A, Shibata AK, Woodbine LJ, Jeggo PA, Chalmers AJ. Sensitization to radiation and alkylating agents by inhibitors of poly(ADP-ribose) polymerase is enhanced in cells deficient in DNA double-strand break repair. Mol Cancer Ther. 2010; 9:1775-1787.

26. van Gent DC, Hoeijmakers JH, Kanaar R. Chromosomal stability and the DNA double-stranded break connection. Nat Rev Genet. 2001; 2:196-206.

27. Borrego-Soto G, Ortiz-Lopez R, Rojas-Martinez A. Ionizing radiation-induced DNA injury and damage detection in patients with breast cancer. Genet Mol Biol. $2015 ; 38: 420-432$.

28. Ashworth A. A synthetic lethal therapeutic approach: poly(ADP) ribose polymerase inhibitors for the treatment of cancers deficient in DNA double-strand break repair. J Clin Oncol. 2008; 26:3785-3790.

29. Evans MK, Longo DL. PALB2 mutations and breast-cancer risk. N Engl J Med. 2014; 371:566-568.

30. Chambon P, Weill JD, Mandel P. Nicotinamide mononucleotide activation of new DNA-dependent polyadenylic acid synthesizing nuclear enzyme. Biochem Biophys Res Commun. 1963; 11:39-43.

31. Albert JM, Cao C, Kim KW, Willey CD, Geng L, Xiao D, Wang H, Sandler A, Johnson DH, Colevas AD, Low J, Rothenberg ML, Lu B. Inhibition of poly(ADP-ribose) polymerase enhances cell death and improves tumor growth delay in irradiated lung cancer models. Clin Cancer Res. 2007; 13:3033-3042.

32. Fong PC, Boss DS, Yap TA, Tutt A, Wu P, MerguiRoelvink M, Mortimer $\mathrm{P}$, Swaisland $\mathrm{H}$, Lau A, O'Connor MJ, Ashworth A, Carmichael J, Kaye SB, et al. Inhibition of poly(ADP-ribose) polymerase in tumors from BRCA mutation carriers. N Engl J Med. 2009; 361:123-134. 
33. Rouleau M, Patel A, Hendzel MJ, Kaufmann SH, Poirier GG. PARP inhibition: PARP1 and beyond. Nat Rev Cancer. 2010; 10:293-301.

34. Mateo J, Carreira S, Sandhu S, Miranda S, Mossop H, Perez-Lopez R, Nava RD, Robinson D, Omlin A, Tunariu N, Boysen G, Porta N, Flohr P, et al. DNA-Repair Defects and Olaparib in Metastatic Prostate Cancer. N Engl J Med. 2015; 373:1697-1708.

35. Moher D, Liberati A, Tetzlaff J, Altman DG. Preferred reporting items for systematic reviews and meta-analyses: the PRISMA statement. Ann Intern Med. 2009; 151:264-269, W64.

36. Stang A. Critical evaluation of the Newcastle-Ottawa scale for the assessment of the quality of nonrandomized studies in meta-analyses. Eur J Epidemiol. 2010; 25:603-605.
37. Zhong Q, Peng HL, Zhao X, Zhang L, Hwang WT. Effects of BRCA1 - and BRCA2-related mutations on ovarian and breast cancer survival: a meta-analysis. Clin Cancer Res. 2015; 21:211-220.

38. Parmar MK, Torri V, Stewart L. Extracting summary statistics to perform meta-analyses of the published literature for survival endpoints. Stat Med. 1998; 17:2815-2834. 